\title{
Impact of Feminism on Narcissism and Tolerance for Disagreement among Females
}

\author{
Sanya Taneja ${ }^{1}$, Prerna Goyal ${ }^{2}$ \\ ${ }^{1,2}$ Department of Psychology, Jamia Millia Islamia University, Delhi \\ Corresponding author: Sanya Taneja \\ Email-tanejasanya3@gmail.com
}

\begin{abstract}
Background: The present study was aimed at discerning the impact of feminism on narcissism and tolerance for disagreement among females.

Methods: For the purpose, a sample of 40 females belonging to the age group of 18-25 years was taken. The participants were divided into two groups: (feminists and non-feminists) on the basis of their self-ratings on the construct of feminism. Each group was assessed for their narcissism and tolerance for disagreement, quantitatively with the help of Dark Triad of Personality (D3-Short; narcissism sub-scale) and Tolerance for Disagreement Scale.

Results: The results of the study indicated that there was a significant difference in the levels of narcissism and tolerance for disagreement, among feminists and non-feminist females. And it was observed that, feminist females elicited a higher level of narcissism with a mean of 2.92, as compared to non-feminist females with a mean of 2.31; and lower levels of tolerance for disagreement was found in feminist females with a mean of 39.00, as opposed to non-feminist females with a mean of 52.15.

Conclusion: There was a significant difference in the levels of narcissism and tolerance for disagreement, among feminist and non-feminist females.
\end{abstract}

Keywords: Feminism, females, narcissism, and tolerance for disagreement.

(Paper received $-28^{\text {th }}$ November 2018, Peer review completed $-20^{\text {th }}$ December 2018)

(Accepted $-27^{\text {th }}$ December 2018)

\section{INTRODUCTION}

\section{Feminism}

Feminism refers to a collection of ideologies which tend to share common goals, to establish, describe, and achieve equal economic, political, cultural, social and also personal rights for women. Therefore, this seeks to establish opportunities that are equal for women in both education and employment [1].

\section{Narcissism}

Narcissism is described as a "pervasive pattern of grandiosity, lack of empathy and need for admiration [2]. The diagnostic criteria comprise: self-importance; preoccupation with success, power, brilliance, and/or beauty; a belief that they are special; a strong sense of entitlement; the tendency to exploit others; arrogance [2]. Narcissistic individuals repeatedly try to seek and obtain signs of recognition to compensate for feelings of inadequacy and so they do not feel comfortable when accomplishments are not appreciated by others [2]. Narcissists seem undermine themselves in their interactions with others, but this may be because they do not possess the self-control that is crucial to allow positive interaction [3]. However, many believe that key to the alleviation of narcissism is simply to learn to love oneself [4]. In fact, as Campbell, Foster, and Finkle argue, self-love can actually come between and even destroy romantic relationships [5]. In reality, what the narcissist is looking for is not always a healthy form of love.

Narcissists tend to view themselves as more attractive and smarter, and all around better than others [6]. 
Jones and Paulhus stated that narcissistic behaviour was marked by manipulation and callousness, much like machiavellianism and psychopathy [7]. Intrapsychically, however, narcissism was defined by a clash between a grandiose identity and underlying insecurity.

Narcissism is negatively correlated with empathy [8]. Narcissist personality disorder overlaps with psychopathy in that they share the same features of arrogance, a lack of empathy, and exploitation of others. The difference is that narcissists are more grandiose in their behaviour while psychopathic individuals may be more underhanded in their behaviour [2].

\section{Tolerance for disagreement}

The construct of Tolerance for Disagreement was recently formulated by Knutson, McCroskey, Knutson, and Hurt [9]. Based upon earlier work in the area of conflict resolution and management, this construct was advanced to explain why some individuals are prone to become involved in conflict situations while others are not. Using the definition of Disagreement as "a difference of opinion on substantive or procedural matters, "Conflict between people is a common feature of the human condition. When people interact and form relationships, disagreements inevitably emerge." Disagreement is common, its result does not have to be destructive, it can be and frequently is constructive [10-11]. McCroskey and Wheeless employed the concept of "tolerance for disagreement" to help explain the threshold individuals have for dealing with interpersonal conflict. They maintained that conflict and disagreement is not the same thing. Disagreement can be thought of as simple difference of opinion [12].

A number of studies have tried to investigate the impact of feminism on narcissism and tolerance for disagreement. Freud argues that for some 'highly complicated biological reason' women as they sexually mature slide back towards the narcissism of their infancy [13].

Coward advocated that women's relationship to cultural ideals, and to their image, could be more accurately described as a relation of narcissistic damage [14]. Similarly, Bartky argues that although overtly 'the fashion-beauty complex seeks to glorify the female body and to provide opportunities for narcissistic indulgence, depreciating the woman's body and dealing a blow to her narcissism, is its covert goal [15]. Fiquet states that there is a strong and positive correlation between feminism and general tolerance, as well as tolerance of homosexuals, atheists and communists. Since, a number of studies have been focused around studying the effect of narcissism among women. However, there have been little or no research conducted to track down the relationship between narcissism and feminism. And, there have been only few studies conducted on tolerance among females. And, in these studies too, tolerance for disagreement has not generally been the focus. Thus, the focus of the present study is to know the effect of feminism on narcissism and on tolerance (particularly, tolerance for disagreement) among females [16].

\section{METHODOLOGY}

The present study was aimed at discerning the impact of feminism on narcissism and tolerance for disagreement among females.

\section{Participants}

A sample of 40 females belonging to the age group of 18-25 years was taken. The sample was further divided into two groups having 20 participants each on the basis whether or not they reported themselves as feminists or non-feminists, respectively.

\section{Instruments}

The following two quantitative tools were used:

Narcissism scale: The Short Dark Triad by Jones and Paulhus [17] was used to assess levels of narcissism in participants. This version had psychopathy, machiavellianism and narcissism sub-scales with a total of twenty seven items, broken down into 9 item subscales. The participants were supposed to respond using a five-point likert type scale ranging from 1 meaning Strongly Disagree to 5 meaning Strongly Agree. The participants were given instructions to score each statement depending on the degree to which they either agreed or disagreed with the statements presented. An example of an item on the narcissism sub-scale is: "I know that I am special because everyone keeps telling me so". The items on the scale have been found to be 
reliable and valid in the studies carried out by Jones and Paulhus. External validity was demonstrated by showing that the Short dark triad scales predicted corresponding informant-ratings. In a study using the scale, researchers found Cronbach's alpha reliability coefficients was 0.71 for narcissism [18]. A study by Egan, Chan, and Shorter (2014) found all three constructs of this scale to be reliable at alpha 0.72 or 13 above [19].

Tolerance for disagreement scale: The Tolerance for Disagreement Scale was developed by Teven, Richmond and McCroskey to measure the degree to which an individual can tolerate other people disagreeing with what the individual believes to be true. The tolerance for disagreement conceptualization is similar to that of argumentativeness and has been developed through research in organizational and group communication contexts [20]. It is a self-report, 15 item scale questionnaire consisting of items, "It is more fun to be involved in a discussion where there is a lot of disagreement". Participants are asked to select the option which best reflects the degree to which they agree that the item relates to them from a 5 point Likert scale ranging from 1 meaning strongly disagree to 5 indicating strongly agree. The tolerance for disagreement was found to have an alpha reliability of 0.86 [20].

\section{STATISTICAL ANALYSIS}

Data collected was scored and descriptive statistics were used to calculate the mean scores and standard deviation scores, along with t-test on the basis of feminism and non-feminism on the Narcissism scale and the Tolerance for disagreement scale.

\section{RESULTS}

Table 1 Shows the mean and standard deviation scores, along with t-test for both the groups with respect to feminism on Narcissism scale and Tolerance for disagreement scale

\begin{tabular}{|c|c|c|c|c|c|c|}
\hline & Feminism & $\mathbf{N}$ & Mean & $\mathbf{t}$ & Significance & $\begin{array}{l}\text { Cohen's } \\
\text { d }\end{array}$ \\
\hline \multirow[t]{2}{*}{ Narcissism } & Feminist & 20 & 2.92 & \multirow{2}{*}{$\begin{array}{l}7.36 \\
2\end{array}$} & \multirow[t]{2}{*}{$0.0001^{*}$} & \multirow[t]{2}{*}{1.26} \\
\hline & Non-feminist & 20 & 2.31 & & & \\
\hline \multirow[t]{2}{*}{$\begin{array}{l}\text { Tolerance for } \\
\text { disagreement }\end{array}$} & Feminist & 20 & 39.00 & \multirow[t]{2}{*}{$\begin{array}{l}3.96 \\
3\end{array}$} & \multirow[t]{2}{*}{$0.0001^{*}$} & \multirow[t]{2}{*}{2.33} \\
\hline & Non-feminist & 20 & 52.15 & & & \\
\hline
\end{tabular}

Looking at Table 1, it is indicated that there is a significant difference in the levels of narcissism of feminists and non-feminists females, $(\mathrm{t}(38)=7.362, \mathrm{p}<.01)$ and it is also observed that, feminist females elicit higher levels of narcissism with the mean of 2.92 as compared to non-feminist females with the mean of 2.31 . The effect size is calculated with the help of Cohen's $d$ formula and it came out to be $d=1.26$, since, the value of the effect size of Cohen's $d$ is higher than 0.7 , this is indicative of a high effect size, which in turn indicates that there is high practicality value of the given data.

\section{DISCUSSION}

According to Jones and Paulhus narcissistic behaviour consists of manipulation and callousness, more or less like machiavellianism and psychopathy. Intra psychically, however, narcissism was defined by a clash between a grandiose identity and underlying insecurity. Freud concluded that for some 'highly complicated biological reason' Women as they sexually mature slide back towards the narcissism of their infancy [13]. Thus, the present study is parallel to the findings of Freud, as strings of narcissism are observed in females. 
However, the present study indicates that feminist females possess a higher level of narcissism, as compared to non-feminist females.According to Teven and others, tolerance for disagreement is the degree to which one acknowledges that differences of opinion exist within relationships, and thus require discussion. Fiquet states that there is a strong and positive correlation between feminism and general tolerance, as well as tolerance of homosexuals, atheists and communists. Consistent to Fiquet's study, the present study tells us that, there is an impact of feminism on tolerance for disagreement; as, feminist females elicited a lower level of tolerance for disagreement as compared to non-feminist females.

\section{CONCLUSION}

Thus, from the present study, it can be concluded that there was a significant difference in the levels of narcissism and tolerance for disagreement, among feminist and non-feminist females. And, it was observed that, feminist females elicited a higher level of narcissism with a mean of 2.92, as compared to non-feminist females with a mean of 2.31; and lower levels of tolerance for disagreement was found in feminist females with a mean of 39.00, as opposed to non-feminist females with a mean of 52.15. But, in order for the results to be generalized to the larger population we need to take into consideration a larger sample size.

\section{REFERENCES}

1. Eagleton M. A concise companion to feminist theory. John Wiley \& Sons; 2008.

2. Coney A. An investigation into the dark triad of personality and fear and startle response among adults. BA Thesis, University of Dublin, Ireland ; 2017.

3. Vazire S, Funder DC. Impulsivity and the self-defeating behavior of narcissists. Personal Soc Psychol Rev 2006;10(2):154-65.

4. Branden N. The psychology of self-esteem: a revolutionary approach to self-understanding that launched a new era in modern psychology. Jossey-Bass; 2001.

5. Campbell WK, Foster CA, Finkel EJ. Does self-love lead to love for others? A story of narcissistic game playing. J Personal Soc Psychol 2002;83(2):340-6.

6. Campbell WK, Rudich EA, Sedikides C. Narcissism, self-esteem, and the positivity of self-views: Two portraits of self-love. Personal Soc Psychol Bull 2002;28(3):358-68.

7. Jones DN, Paulhus DL. The role of impulsivity in the Dark Triad of personality. Personal Individ Diff 2011;51(5):679-82.

8. Watson PJ, Grisham SO, Trotter MV, Biderman MD. Narcissism and empathy: Validity evidence for the Narcissistic Personality Inventory. J Personal Assess 1984;48(3):301-5.

9. Teven JJ, McCroskey JC, Richmond VP. Measurement of tolerance for disagreement. Commun Res Rep 1998;15(2):209-17..

10. Coser LA. The functions of social conflict. Routledge; 1998.

11. Deutsch M. The resolution of conflict: Constructive and destructive processes. Yale University Press; 1977.

12. Thweatt KS, McCroskey JC. The impact of teacher immediacy and misbehaviors on teacher credibility. Commun Educ 1998;47(4):348-58.

13. Bateman A, Holmes J. Introduction to psychoanalysis: Contemporary theory and practice. Routledge; 2002.

14. Desire F. Women's Sexuality Today. London: Paladin. 1984.

15. Bartky SL. Femininity and domination: Studies in the phenomenology of oppression. Routledge; 2015.

16. Fiquet Jr AT. An Analysis of Tolerance Variation Among Adherents to Feminist, Environmentalist and Gay Rights Principles (Doctoral dissertation, Virginia Tech) ; 1998.

17. Jones DN, Paulhus DL. Introducing the short dark triad (SD3) a brief measure of dark personality traits. Assessment 2014;21(1):28-41.

18. Baughman HM, Dearing S, Giammarco E, Vernon PA. Relationships between bullying behaviours and the Dark Triad: A study with adults. Personal Individ Diff 2012;52(5):571-5.

19. Egan V, Chan S, Shorter GW. The Dark Triad, happiness and subjective well-being. Personal Individ Diff 2014;67:17-22.

20. Teven JJ. Teacher Socio-Communicator Style and Tolerance for Disagreement and their Association with Student Learning in the College Classroom. Texas Speech Communication Journal 2005;30(1).

$* * * * * * * * * * * * * * * * * * * * * * * * * * * * * * * * * * * *$

Acknowledgements - Nil ; Conflict of Interest - Nil ; Funding - Nil

Indian Journal of Mental Health 2019;6(1) 